\title{
Antibiotics prescription pattern and compliance for common childhood illnesses - an observational study
}

\author{
Shanthi A.K. ${ }^{1}$, Barathy C. ${ }^{2}$, Antonieo J.R. ${ }^{3}$, Devagaran V. ${ }^{4}$ \\ ${ }^{1}$ Dr. Shanthi A.K, Professor of Paediatrics, ${ }^{2}$ Dr. C. Barathy, Assistant Professor, ${ }^{3}$ Dr. Antonieo Jude Raja, Senior \\ Resident, ${ }^{4}$ Dr. Vijaya Devagaran, Senior Resident, all authors are affiliated with Department of Pediatrics, Indira \\ Gandhi Medical College and Research Institute, Kadirkamam, Puducherry, India.
}

Address for Correspondence: Dr. C. Barathy, Assistant Professor, Department of Paediatrics, Indira Gandhi Medical College and Research Institute, Kadirkamam, Puducherry. Email: barathy_c@rediffmail.com

\begin{abstract}
Introduction: Antibiotics are generally overused in children. Frequent inappropriate use of antibiotics and poor compliance contributes to antibiotic resistance. An observational study was undertaken to determine the pattern of antibiotic use and compliance for common ailments in children attending a tertiary care hospital in Puducherry, South India. Methods: Data was obtained from 197 consecutive children who had visited a health care provider during the previous two weeks for any ailment, in a pretested semi structured questionnaire. Data was entered on MS Excel spreadsheet and analysed using Stata14.0 (Stata Corp, College Station, Tx). Chi square test with Fisher's modification and logistic regression models were used in the analysis. Results: Acute respiratory infections were the most common infections in all age groups followed by diarrheal disorders in infants and fever in older children. Proportion of illnesses which received antibiotics was $75 \%$ for respiratory illnesses, $78 \%$ for fever, $50 \%$ for diarrheal disorders and $64 \%$ for other infections, there being no statistically significant difference between them. Out of 143 children who were prescribed antibiotics, 127 (89\%) gave the medicines as prescribed. However, only $53(37 \%)$ completed the full course of antibiotics. Compliance with treatment was not associated with age or the type of illness. Most of the parents $(73 \%)$ discontinued antibiotics because of worsening of symptoms. Adverse reaction to antibiotics was seen in $32(22 \%)$ children. Conclusion: Overuse of antibiotics for common ailments and poor compliance with treatment were perhaps important contributory causes for development of antimicrobial resistance in this region.
\end{abstract}

Key words: Antibiotic resistance, Prescription, Patient Compliance, Diarrhea, Fever, Respiratory Tract infection

\section{Introduction}

Antibiotics are one of the most widely used medications in children, prescribed by both public and private health care providers. However, their use is not always rational. Problem of overprescripton exists globally. Studies across the globe have revealed overuse of antibiotics in a sick child $[1,2]$. Prescription of antibiotics for a sick child is influenced by several factors and shows a wide variation across countries, health care settings, age of the child, season, type of practice, prescribing physicians etc.[3-5]. It has been observed that a higher proportion of sick children are prescribed antibiotics compared to sick adults $[2,6]$.

Manuscript received: $25^{\text {th }}$ November 2017

Reviewed: $4^{\text {th }}$ December 2017

Author Corrected: $10^{\text {th }}$ December 2017

Accepted for Publication: $16^{\text {th }}$ December 2017
Frequent inappropriate use leads to the emergence of drug-resistant micro-organisms [1,7,8]. Poor compliance to prescribed antibiotics also contributes to the same. Antimicrobial resistance is thus a great challenge to health care providers.

It necessitates the identification of various contributory factors and interventions to prevent the emergence of drug resistance, particularly due to in appropriate antibiotic usage.

Several interventions including auditing, training on rational use of drugs, framing guidelines and so on are being taken all over the world to regulate the use of antibiotics [9-11]. 
Besides the problem of antibiotic resistance, adverse reactions and economic burden has to be addressed. Since the pattern of antibiotic usage in children varies across the globe, it has to be addressed regionally and locally so that suitable interventions can be planned to restrict antibiotic usage.

Therefore, we have undertaken this prospective study to determine the pattern of antibiotic use and compliance for common ailments in children attending a tertiary care hospital in Puducherry, South India.

The common childhood illnesses encountered and drugs prescribed for them by both public and private practioners was investigated. The compliance and reasons for poor compliance if any was studied.

\section{Materials and Methods}

Study Design: An observational study

Place of study: The study was conducted in the Paediatric department of Indira Gandhi Medical College and Research Institute, a tertiary care hospital in Puducherry, South India after approval from Institute Ethics Committee

Inclusion criteria: Children who had visited a hospital or a physician in the previous two weeks for any ailment.

\section{Results}

Data was obtained from 200 children. Three were excluded due to incomplete information and 197 children were included in the final analysis. Out of 197 children, 53 (27\%) were $\leq 1$ year of age, $87(44 \%)$ between 1-5 years of age and $57(29 \%) \geq 5$ years of age. Sample distribution is similar to the proportion of children attending the Paediatrics department in our hospital. The mean maternal and paternal ages were $27.6 \pm 4$ years and $33.2 \pm 5$ years respectively. The literacy rate was $94 \%$ among parents.

Illnesses seen in various age groups is given in Table 1.

Table-1: Common illnesses seen in different age groups.

\begin{tabular}{|c|c|c|c|c|}
\hline \multirow{2}{*}{ Age } & \multicolumn{3}{|c|}{ Common illnesses } \\
\cline { 2 - 5 } & ARI $\mathrm{n}(\%)$ & Fever $\mathrm{n}(\%)$ & Diarrheal disorders $\mathrm{n}(\%)$ & Others $\mathrm{n}(\%)$ \\
\hline$\leq 1$ year $(\mathrm{n}=53)$ & $36(68)$ & $5(9)$ & $9(17)$ & $3(6)$ \\
\hline $1-5$ years $(\mathrm{n}=87)$ & $54(62)$ & $22(25)$ & $7(8)$ & $4(5)$ \\
\hline$\geq 5$ years $(\mathrm{n}=57)$ & $29(51)$ & $19(33)$ & $2(4)$ & $7(12)$ \\
\hline
\end{tabular}

$\mathrm{ARI}=$ Acute Respiratory Infections.

Acute respiratory infections were the most common infections in all age groups. While this was followed by diarrheal disorders in infants, fever was the next common illness in older children. The point of primary care was the private sector in $162(82 \%)$ children and the public sector in $35(18 \%)$. 
Out of 197 children, 143(73\%) were prescribed antibiotics. Proportion of children receiving antibiotics were $68 \%$ (36/53), $72 \%(63 / 87)$ and $77 \%(44 / 57)$ in the age groups $\leq 1$ year, 1-5 years and $\geq 5$ years respectively.

Antibiotic prescription rates were $72 \%(116 / 162)$ and $74 \%(26 / 35)$ respectively in the private and public health care facilities with no statistically significant difference between them.

Antibiotics prescribed for various illnesses are given in Table 2.

Table- 2: Proportion of various illnesses prescribed antibiotics.

\begin{tabular}{|c|c|c|c|c|}
\hline Illness & $\begin{array}{c}\text { Number prescribed antibiotics } \\
\mathbf{n}(\%)\end{array}$ & p value & OR & 95\% CI \\
\hline ARI (n=119) & $89(75)$ & 0.35 & 2.97 & $1.08-8.16$ \\
\hline Fever (n=46) & $36(78)$ & 0.030 & 3.6 & $1.13-11.48$ \\
\hline Diarrheal disorders (n=18) & $9(50)$ & Reference & 1.0 & - \\
\hline Others (n=14) & $9(64)$ & 0.42 & 1.80 & $0.40-2.52$ \\
\hline
\end{tabular}

$\mathrm{ARI}=$ Acute Respiratory Infections

Although a higher proportion of patients with respiratory illness and fever were prescribed antibiotics compared to diarrheal disorders, this difference was not statistically significant. $(\mathrm{p}=0.105)$.

Out of 143 children who were prescribed antibiotics, 127 (89\%) gave the dose as prescribed by the doctor.

The others gave less than the prescribed dose for they felt that the child may not tolerate a high dose.

The proportion of children given the prescribed dose of antibiotics is similar in the three age groups being $83 \%$, $90 \%$ and $91 \%$ respectively.

However, it was observed that only 53 (37\%) children out of 143 completed the full course of antibiotics (Tables 3 and 4).

Table- 3: Proportion of children in different age groups who have completed full course of antibiotics.

\begin{tabular}{|c|c|c|c|c|}
\hline $\begin{array}{c}\text { Age } \\
\text { (n= no. prescribed } \\
\text { antibiotics) }\end{array}$ & $\begin{array}{c}\text { Completed antibiotic course } \\
\mathbf{n}(\%)\end{array}$ & p value & OR & 95\% CI \\
\hline$\leq 1$ year $(\mathrm{n}=36)$ & $16(44)$ & Reference & 1.0 & \\
\hline $1-5$ years $(\mathrm{n}=63)$ & $23(37)$ & 0.44 & 0.72 & $0.31-1.65$ \\
\hline$\geq 5$ years $(\mathrm{n}=44)$ & $14(32)$ & 0.25 & 0.58 & $0.23-1.45$ \\
\hline
\end{tabular}


Original Research Article

Table- 4: Proportion of children with different types of illnesses who have completed full course of antibiotics.

\begin{tabular}{|c|c|c|c|c|c|}
\hline IIIness & $\begin{array}{c}\text { Number given } \\
\text { antibiotics }\end{array}$ & $\begin{array}{c}\text { No. Completed course } \\
\mathbf{n}(\%)\end{array}$ & p value & OR & $\mathbf{9 5 \%}$ CI \\
\hline ARI & 89 & $33(37)$ & 0.38 & 2.06 & $0.40-10.52$ \\
\hline Fever & 36 & $16(44)$ & 0.24 & 2.8 & $0.51-15.38$ \\
\hline Diarrheal disorders & 9 & $2(22)$ & Reference & 1.0 & - \\
\hline Others & 9 & $2(22)$ & 1 & 1.0 & $0.11-9.23$ \\
\hline
\end{tabular}

ARI $=$ Acute Respiratory Infections

There was no association between completing the course of antibiotics and different age groups or type of illness. The reasons for not completing the course of antibiotics were worsening of symptoms in 66 (73\%), adverse reaction to drugs in $17(19 \%)$ and improvement in symptoms in seven $(8 \%)$.

Adverse reaction to antibiotics was seen in only $32(22 \%)$ children. These were vomiting, diarrhoea and skin rashes in $28(20 \%)$, three ( $2 \%)$ and one (1\%) respectively. Out of 36,63 and 44 children in the age groups $\leq 1$ year, $1-5$ years and $\geq 5$ years respectively the corresponding number of children developing adverse reactions were 11 $(31 \%), 12(19 \%)$ and $9(20 \%)$ with no statistically significant difference between them $(\mathrm{p}=0.39)$.

\section{Discussion}

This study has shown that $73 \%$ of children who seek health care are prescribed antibiotics. Although this is less than over $80 \%$ reported by some investigators, it is higher than that observed in some studies, where the antibiotic prescription rates range from $35 \%$ to $65 \%$ [12-14].

The difference in the prescription rates observed in various studies could be due to differences in the severity of illness, health care settings, prescribing doctors etc which have a bearing on prescription practices.

It has been observed that antibiotic prescription rates are higher with general practioners as compared to specialists $[3][15,16]$.

However, we found similar rates of prescription by both public and private health care providers being $72 \%$ and $74 \%$ respectively.
Common reasons for which children seek health care are respiratory infections, fever and diarrheal illness [13] [17,18]. The most common indication for antibiotic prescription was fever in this study which is similar to that reported by Kumar et al [7].

However, it is at variance with several other studies where acute respiratory infection was the commonest indication for antibiotic prescription $[2,14,19]$.

This again could be due to the difference in the prevalence of illnesses in different regions. While respiratory infection in general and otitis media in particular seem to be the common infections for which antibiotics are prescribed in developed countries, supposed blood stream infections like salmonella, malaria seem to be more common for antibiotic prescription in developing countries [7]. 
Our study showed that $75 \%$ of children with respiratory infections were prescribed antibiotics which is similar to $79.9 \%$ observed by Barathyraja et al [20]. Prescription rate for respiratory infections shows a wide variation ranging from 10\% - 50\% $[21,22]$.

Although there are guidelines for prescribing antibiotics for acute respiratory infections, these were not strictly adhered to in many instances resulting in over prescription [1]. High prescription rate of antibiotics for respiratory infections could be because of the perceived severity of the illness by both physician and parent [22].

The lowest rate of antibiotic prescription seen in this study was for diarrheal illnesses being 50\%. This is higher than that observed by some, where $44 \%$ of diarrheal illnesses received antibiotics, but much lower than over $70 \%$ reported by some investigators $[23,24]$.

Despite World Health Organization (WHO) guidelines for managing diarrheal illness being in practice for several decades, our findings suggest that there continues to be overuse of antibiotics for this condition.

We observed that only $38 \%$ of those given antibiotics completed the course. This is lower than that observed in Bangladesh where more than $60 \%$ of patients had completed their full course of antibiotics [25].

There are several reasons for not complying with treatment such as intolerance, dosing frequency, and clinical improvement. However, we found that the most common reason for non-compliance was worsening of symptoms. It is possible that parents get alarmed when a child does not show immediate

\section{Original Research Article}

response to treatment and keep hopping from doctor to doctor without realizing the implications of not completing the course of antibiotic prescribed. Noncompliance is perhaps due to both overanxious parents and doctors who are not prepared to wait and watch.

WHO has launched antibiotic stewardship program on world health day in 2011 to restrict the use of antibiotics [11].

Several measures are being taken for restricting the use of antibiotics such as judicious use of lab investigations, interventions that include educating parents and changing clinicians' behavior, enforcing strict adherence to guidelines which have significantly reduced the use of antibiotics $[9,10]$ [21]

\section{Conclusion}

This study shows overuse of antibiotics for acute illnesses in children and poor patient compliance, both of which significantly contribute to development of antibiotic resistance. There was no significant difference in the prescription rates of antibiotics between private and public health care providers.

The need of the hour is launching educational and professional campaigns in the community targeting both physicians and parents to limit antibiotic usage and improve compliance.

This could go a long way in making optimum use of antibiotic in children and may help in combating antimicrobial resistance.

Key words: Antibiotic resistance, Prescription, Patient Compliance, Diarrhea, Fever, Respiratory Tract infections 
What is already known- Antibiotics are generally overused in children

\section{What this study adds}

- Proportion of common childhood illnesses such as fever, respiratory infections and diarrheal disorders that are prescribed antibiotics

- Compliance with antibiotic use and reasons for non-compliance

\section{Abbreviations used \\ OR- Odd's ratio, CI-Confidence interval, ARI- Acute respiratory infections, WHO-World Health Organisation}

Funding: Nil, Conflict of interest: None initiated, Perission from IRB: Yes

\section{Authors' contribution}

${ }^{1}$ Dr. Shanthi AK, ${ }^{2}$ Dr. C. Barathy, ${ }^{3}$ Dr. Antonieo Jude Raja, ${ }^{4}$ Dr. Vijayadevagaran

1. Concept, Design of the work, Data acquisition, Data analysis, drafting the work, editing and revising it critically and final approval of the version

2. Design of the work, Data acquisition, Data analysis, drafting the work, editing and revising it critically and final approval of the version

3. Data acquisition and data analysis

4. Data acquisition and data analysis

\section{References}

1. Ayyad S, Al-Owaisheer A, Al-Banwan F, AlMejalli A, Shukkur M, Thalib L. Evidence-based practice in the use of antibiotics for respiratory tract infections in primary health centers in Kuwait. Med Princ Pract. 2010;19(5):339-43. doi: 10.1159/ 0003 16369. Epub 2010 Jul 14.

\section{Original Research Article}

2. Batwala V, Magnussen P, Nuwaha F. Antibiotic use among patients with febrile illness in a low malaria endemicity setting in Uganda. Malar J. 2011

Dec 20;10:377. doi: 10.1186/1475-2875-10-377.

3. Abbas S, Ihle P, Heymans L, Kupper-Nybelen J, Schubert I. Differences in antibiotic prescribing between general practitioners and pediatricians in Hesse, Germany.Dtsch Med Wochenschr.2010 Sept; 135(37):1792-97.doi:10.1055/s-0030-1263321.

4. Chandy SJ, Thomas K, Mathai E, Antonisamy B, Holloway KA, Stalsby Lundborg C. Patterns of antibiotic use in the community and challenges of antibiotic surveillance in a lower-middle-income country setting: a repeated cross-sectional study in Vellore, South India. J Antimicrob Chemother. 2013 Jan; 68 (1): 229-36. doi: 10.1093/jac/dks355. Epub 2012 Sep 3.

5. Pathak A, Mahadik K, Dhaneria SP, Sharma A, Eriksson B, Lundborg CS. Antibiotic prescribing in outpatients: Hospital and seasonal variations in Ujjain, India. Scand J Infect Dis. 2011 Jul; 43(6-7): 479-88. doi: 10.3109/00365548.2011.554854. Epub 2011 Feb 7.

6. Bapna JS, Tekur U, Gitanjali B, Shashindran $\mathrm{CH}$, Pradhan SC, Thulasimani M, Tomson G. Drug utilization at primary health care level in southern India. Eur J Clin Pharmacol. 1992;43(4):413-5.

7. Kumar R, Indira K, Rizvi A, Rizvi T, Jeyaseelan L.Antibiotic prescribing practices in primary and secondary health care facilities in Uttar Pradesh, India. J Clin Pharm Ther. 2008 Dec;33(6):625-34. doi: 10.1111/j.1365-2710.2008.00960.x.

8. Hadi U, Duerink DO, Lestari ES, Nagelkerke NJ, Keuter M, Huis In't Veld D, Suwandojo E, Rahardjo E, van den Broek P, Gyssens IC; Antimicrobial Resistance in Indonesia: Prevalence and Prevention. 
Audit of antibiotic prescribing in two governmental teaching hospitals in Indonesia. Clin Microbiol Infect. 2008 Jul;14(7):698-707. doi: 10.1111/j.14690691.2008.02014.x.

9. Casey JR, Marsocci SM, Murphy ML, Francis $\mathrm{AB}$, Pichichero ME. White blood cell count can aid judicious antibiotic prescribing in acute upper respiratory infections in children. Clin Pediatr (Phila). 2003 Mar;42(2):113-9.

10. Vodicka TA, Thompson M, Lucas P, Heneghan C, Blair PS, Buckley DI, Redmond N, Hay AD; TARGET Programme team. Reducing antibiotic prescribing for children with respiratory tract infections in primary care: a systematic review. $\mathrm{Br} \mathrm{J}$ Gen Pract. 2013 Jul;63(612):e445-54. doi: 10.3399/ bjgp13X669167.

11. Cantón R, Bryan J. Global antimicrobial resistance: from surveillance to stewardship. Part 2: stewardship initiatives. Expert Rev Anti Infect Ther. 2012 Dec;10(12):1375-7. doi: 10.1586/eri.12.140.

12. Bozic B, Bajcetic $M$. Use of antibiotics in paediatric primary care settings in Serbia. Arch Dis Child. 2015 Oct; 100 (10):966-9. doi: 10.1136/ archdischild -2015-308274. Epub 2015 May 20.

13. De Luca $M$, Dona $\mathrm{D}$, Montagnani $\mathrm{C}$, Lo Vecchio A,Romanengo M,Tagliabue C, et al. Antibiotic Prescriptions and Prophylaxis in Italian Children. Is It Time to Change? ARPEC Project PLoS One. 2016; 11: e0154662. https://doi.org/ 10. 1371/journal.pone.0154662

14. Borras Novell C, Hernandez Bou S, Garcia Garcia J J. Prescribing of antibiotics in patients admitted from Emergency Departments: a multicenter study.An Pediatr (Barc).2013July;79 (1):1520. doi: $10.1016 /$ j.anpedi.2012.09.003
Original Research Article

15. Sharma M, Damlin A, Pathak A, Lundborg S C. Antibiotic Prescribing among Pediatric Inpatients with Potential Infections in Two Private Sector Hospitals in Central India. PLoS One; 2015;10 e0142317.https://doi.org/10.1371/journal.pone. 0142 317.

16. Siddiqi S, Hamid S, Rafique G, Chaudhry SA, Ali N, Shahab S, Sauerborn R. Prescription practices of public and private health care providers in Attock District of Pakistan. Int $\mathrm{J}$ Health Plann Manage. 2002 Jan-Mar; 17(1):23-40.

17. Holstiege J, Garbe E. Systemic antibiotic use among children and adolescents in Germany: a population-based study. Eur J Pediatr. 2013 Jun;172 (6): 787-95. doi: 10.1007/s00431-013-1958-y. Epub 2013 Feb 10

18. Koura K G, Garcia A, Todoegnon B, Deloron P, Cot M, Faucher J F. Prevalence and factors related to antibiotic prescription in Benin: a school-based study. Acta Trop.2013 Aug;127(2):87-90. doi: 10. 1016/j. actatropica.2013.04.004

19. Nizami SQ, Khan IA, Bhutta ZA. Paediatric prescribing in Karachi. J Pak Med Assoc. 1997 Jan; 47 (1):29-32.

20. Bharathiraja R,Sridharan S, Chelliah LR, Suresh S, Senguttuvan M. Factors affecting antibiotic prescribing pattern in pediatric practice. Indian $\mathrm{J}$ Pediatr. 2005 Oct;72(10):877-9.

21. Angoulvant F, Skurnik D, Bellanger H, Abdoul $\mathrm{H}$, Bellettre X, Morin L, et al. Impact of implementing French antibiotic guidelines for acute respiratory-tract infections in a paediatric emergency department, 2005-2009. Eur J Clin Microbiol Infect Dis. 2012 July; 31(7): 1295-1303. doi $=10.1007 / \mathrm{s} 10096-011-1442-4$. 


\section{Original Research Article}

22. De Brasi D, Pannuti F, Antonelli F, de Seta F, Siani P, de Seta L. Therapeutic approach to bronchiolitis: why pediatricians continue to over prescribe drugs? Ital J Pediatr. 2010 Oct 1;36: 67. doi: 10.1186/1824-7288-36-67.

23. Osatakul S, Puetpaiboon A. Appropriate use of empirical antibiotics in acute diarrhoea: a crosssectional survey in southern Thailand. Ann Trop Paediatr. 2007 Jun;27(2):115-22.

24. Pathak D, Pathak A, Marrone G, Diwan V, Lundborg CS. Adherence to treatment guidelines for acute diarrhoea in children up to 12 years in Ujjain, India--a cross-sectional prescription analysis. BMC Infect Dis. 2011 Jan 28;11:32. doi: 10.1186/14712334-11-32.

25. Biswas M, Roy D N, Tajmim A, Rajib S S, Hossain M, Farzana F, Yasmen N.Prescription antibiotics for outpatients in Bangladesh: a crosssectional health survey conducted in three cities. Ann Clin Microbiol Antimicrob.2014 Apr;13: 15. https://doi.org/10.1186/1476-0711-13-15.

\section{How to cite this article?}

Shanthi A.K, Barathy C, Antonieo J.R, Devagaran V. Antibiotics prescription pattern and compliance for common childhood illnesses- an observational study. Int J Pediatr Res. 2017;4(12):698-705.doi:10. 17511/ijpr.2017.i12.01. 